\title{
Application of Matrix-Assisted Laser Desorption/lonization Imaging Mass Spectrometry
}

\author{
Nobuhiro Zaima \\ Department of Applied Biological Chemistry, \\ Graduate School of Agriculture, Kinki University \\ Japan
}

\section{Introduction}

The clarification of metabolic dynamics in lesion areas is important. Many approaches, such as high performance liquid chromatography mass spectrometry, gas chromatography mass spectrometry, immunohistochemistry, are used to define disease-related abnormalities. Matrix-assisted laser desorption/ionization imaging mass spectrometry (MALDI-IMS) is attracting attention as a new valuable tool. MALDI-IMS is a two-dimensional MALDI mass spectrometric technique used to visualize the spatial distribution of molecules without extraction, purification, separation, or labeling of biological samples (Cornett et al., 2007; Zaima et al., 2010b). MALDI-IMS has revealed the characteristic distribution of several biomolecules, including proteins (Caprioli et al., 1997; Groseclose et al., 2007; Morita et al., 2010), peptides (Chansela et al., 2011; Stoeckli et al., 2002), amino acids (Goto-Inoue et al., 2010b; Zaima et al., 2010a), lipids (Hayasaka et al., 2009; Murphy et al., 2009; Zaima et al., 2011a), and carbohydrates (Goto-Inoue et al., 2010b), in various tissues. The versatility of MALDI-IMS has opened a new frontier in several fields, such as pharmacology, medicine, agriculture, biology, and pathology. In this review, we describe the methodology and applications of MALDI-IMS for biological samples.

\section{MALDI-MS}

MALDI-MS was developed from laser desorption/ionization mass spectrometry (LDI-MS). The first LDI-MS experiment for high-mass molecules was reported in 1987 (Tanaka et al., 1987). In this experiment, a powder of cobalt metal in glycerol was used for the observation of ions with a mass to charge $(\mathrm{m} / \mathrm{z})$ ratio of 34,000 . Soon afterward, MALDI-MS results of serum albumin $(67,000 \mathrm{Da})$ were reported using nicotinic acid as the matrix (Karas \& Hillenkamp, 1988). It was reported that MALDI-MS can detect a wide range of molecules ranging from small $(m / z<1000)$ to large molecules $(m / z>1,000,000)$ (Yates, 1998). The schema of MALDI-MS is shown in Figure 1.

In routine MALDI-MS analysis (i.e., non-imaging analysis), the analyte can be mixed with an excess of matrix. On the other hand, molecular imaging of tissue sections using MALDIIMS requires the tissue surface to be homogeneously covered by a matrix. On-tissue 
application of matrix results in the in situ extraction of molecules from biological tissues. The cocrystal of matrix and analyte molecules in tissue is irradiated with a pulsed laser of appropriate energy, leading to desorption and ionization of the matrix and analyte molecules. The fragmentation of analyte molecules is prevented by the incorporation of the analyte molecules into matrix crystals. The role of the optical absorption of the matrix in the transfer of energy from the laser beam to the analyte molecules is governed by Beer's law, as described previously (Karas et al., 1985). However, the mechanisms underlying the formation of charged matrix and analyte molecules in the MALDI process are not fully understood.

\section{Mass analyzer}

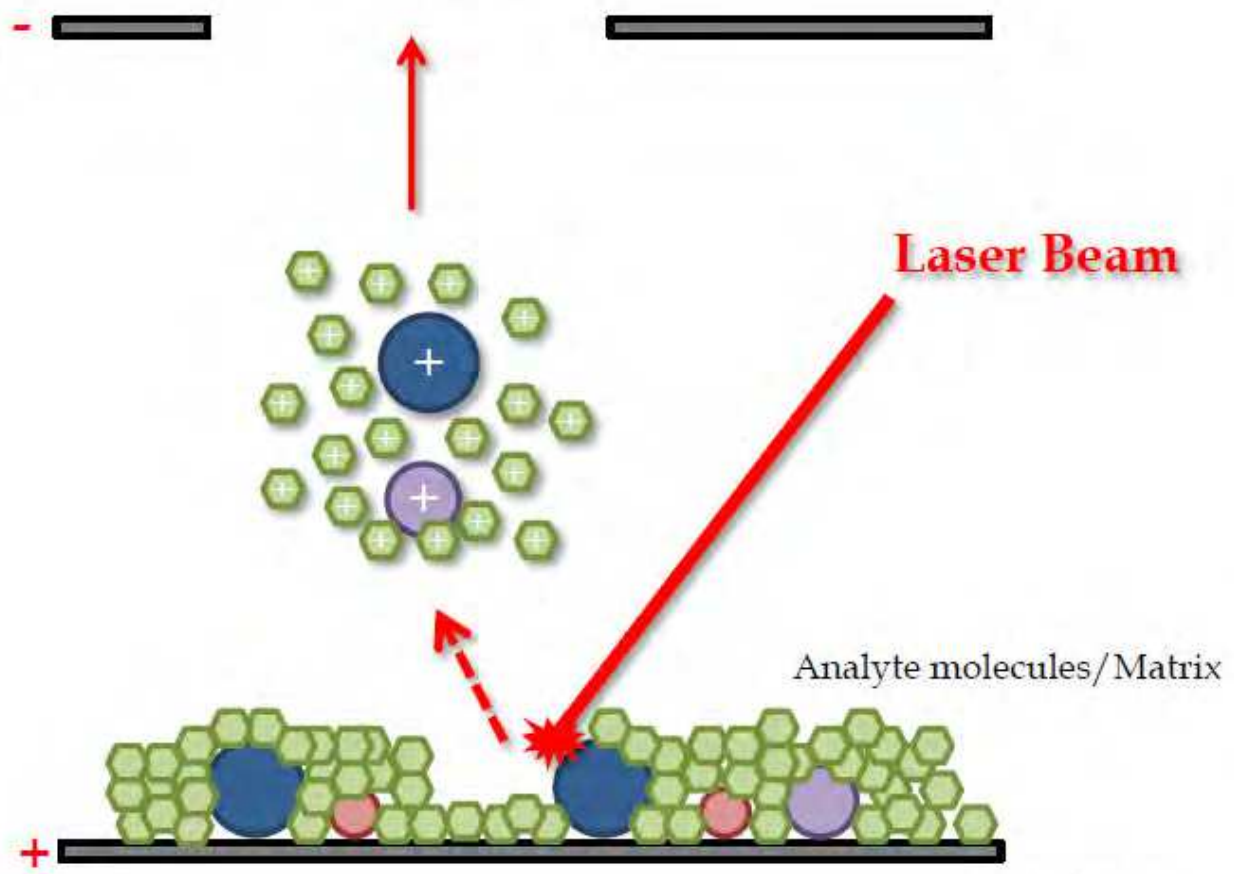

Glass slide

Fig. 1. Schema of MALDI-MS.

The matrix molecules absorb the laser energy and facilitate desorption and ionization of analyte molecules in the tissue. The homogeneous matrix cover is important for MALDIIMS, because a heterogeneous distribution of matrix results in different ionization efficiencies of analyte molecules based on their location.

\section{Methodology of MALDI-IMS}

The important experimental steps for visualizing endogenous molecules or administered pharmaceutical agents in tissue using MALDI-IMS are sample preparation (such as fixation, 
sectioning, and washing), choice of matrix and matrix application, measurement, and data analysis. To obtain meaningful biological images, all steps need to be carefully controlled. In this section, the basic experimental MALDI-IMS procedures are described. The schema of MALDI-IMS is presented in Figure 2.

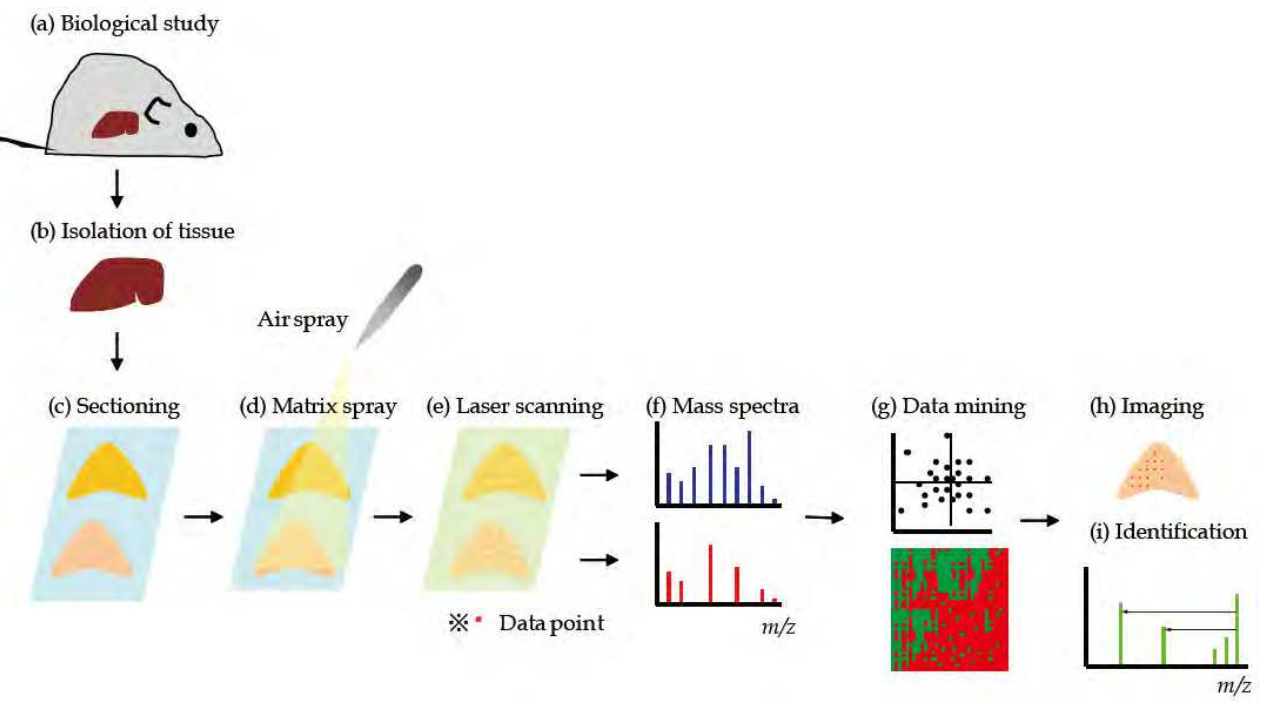

Fig. 2. Schema of MALDI-IMS.

After biological study (a), the tissue of interest should be appropriately isolated (b). A thin section of isolated tissue is mounted on a glass slide (c), coated with matrix (d), and measured by a mass spectrometer (e). The resultant mass spectra (f) can be used for a data mining approach (g). Molecules of interest can be visualized (f) and identified by MS/MS on tissue (f).

\subsection{Biological sample preparation}

The samples for MALDI-IMS come from a variety of biological sources, including organs, whole animal body dosed with a pharmaceutical compound, or pathological tissues. Optimization of the sample preparation procedure according to the chemical and physical properties of analytes is important. Here, the basic sample preparation steps for MALDIIMS are described.

\subsubsection{Sample condition for MALDI-IMS}

Collection and treatment procedures need to be sufficiently fast to prevent rapid tissue degradation, because the sample degradation process starts immediately after the cessation of blood flow. The most preferred sample for MALDI-IMS is a chemically unmodified freshfrozen one. Fresh-frozen samples can be prepared using dry ice, liquid nitrogen, or liquid nitrogen-chilled isopentane, and can be preserved in a deep freezer until required. The samples should be well sealed to prevent drying during storage, and it is important to ensure that the tissue section morphology is well preserved before MALDI-IMS. 


\subsubsection{Fixation and embedding}

Fixation of samples, such as formalin fixation, is preferably avoided because the protein crosslinking introduced by formalin fixation makes MALDI-IMS analysis difficult. However, many medical samples are routinely formaldehyde-fixed and paraffin-embedded (FFPE) just after dissection. To address this problem, the on-tissue proteolytic digestion method, in which proteins are denatured and digested by enzymes, has been developed (Djidja et al., 2009; Groseclose et al., 2007; Lemaire et al., 2007; Morita et al., 2010). The ontissue proteolytic digestion method includes a paraffin removal step using xylene and ethanol. In the paraffin removal step, lipophilic molecules are lost; therefore, FFPE samples cannot be used for lipid imaging. When the samples are formaldehyde-fixed without paraffin-embedding, lipid imaging can be performed (Zaima et al., 2011c). However, the detected ion intensities of lipids in formaldehyde-fixed samples are lower than those in fresh-frozen ones are.

Embedding of the tissue samples in supporting material, such as an optimal cutting temperature (OCT) compound, allows the maintenance of tissue morphology and precise sample sectioning. However, supporting materials are often ionized during MALDI-MS analysis and sometimes act as ion suppressors of molecules of interest (Schwartz et al., 2003). Therefore, samples should not be embedded if precise sample sections can be prepared without embedding. When it is difficult to prepare a sample section, the use of carboxymethylcellulose (CMC) or gelatin as embedding material is recommended. Sodium CMC $(2 \%)$ is reported to be used as an alternative embedding compound that does not interfere with the detection sensitivity of biomolecules in MALDI-IMS analysis (Stoeckli et al., 2006; Zaima et al., 2010a). Chen et al. reported that gelatin provides a cleaner signal background than OCT (Chen et al., 2009). Researchers should ensure compatibility between the supporting material and the biomolecules of interest.

\subsubsection{Sectioning}

The basic sectioning procedure for MALDI-IMS samples is same as that for pathological examination. Sections for MALDI-IMS can be prepared using a cryostat. The sample stage temperature is typically maintained between -5 and $-20^{\circ} \mathrm{C}$. To obtain high quality sections from tissues with high fat content (e.g., brain), or atherosclerotic lesions, breast tissue, or lipid storage disease samples lower temperatures are required. In general, 5-20- $\mu$ m-thick sections are prepared for the analysis of low-molecular-weight molecules. The use of thinner tissue sections (2-5 $\mu \mathrm{m}$ thick) has been recommended for the analysis of high-molecularweight molecules (range, 3-21 kDa) (Goodwin et al., 2008). Sections are usually thawmounted on a stainless steel conductive stage or on commercially available indium-tin oxide (ITO)-coated glass slides. We recommend the use of ITO-coated glass slides because these transparent slides enable microscopic observation of the section after MALDI-IMS. Use of adhesive film is suitable for samples for which thaw-mounted preparation of sections is challenging (e.g., bone or whole-body sections) (Stoeckli et al., 2006; Zaima et al., 2010a). The procedure for sectioning using adhesive film is shown in Figure 3. The prepared section should be immediately dried in a vacuum desiccator to avoid moisture condensation that could cause delocalization of analyte molecules in the tissue. Moisture condensation can be avoided by placing the prepared section in a dry and cold container until return to room temperature. 

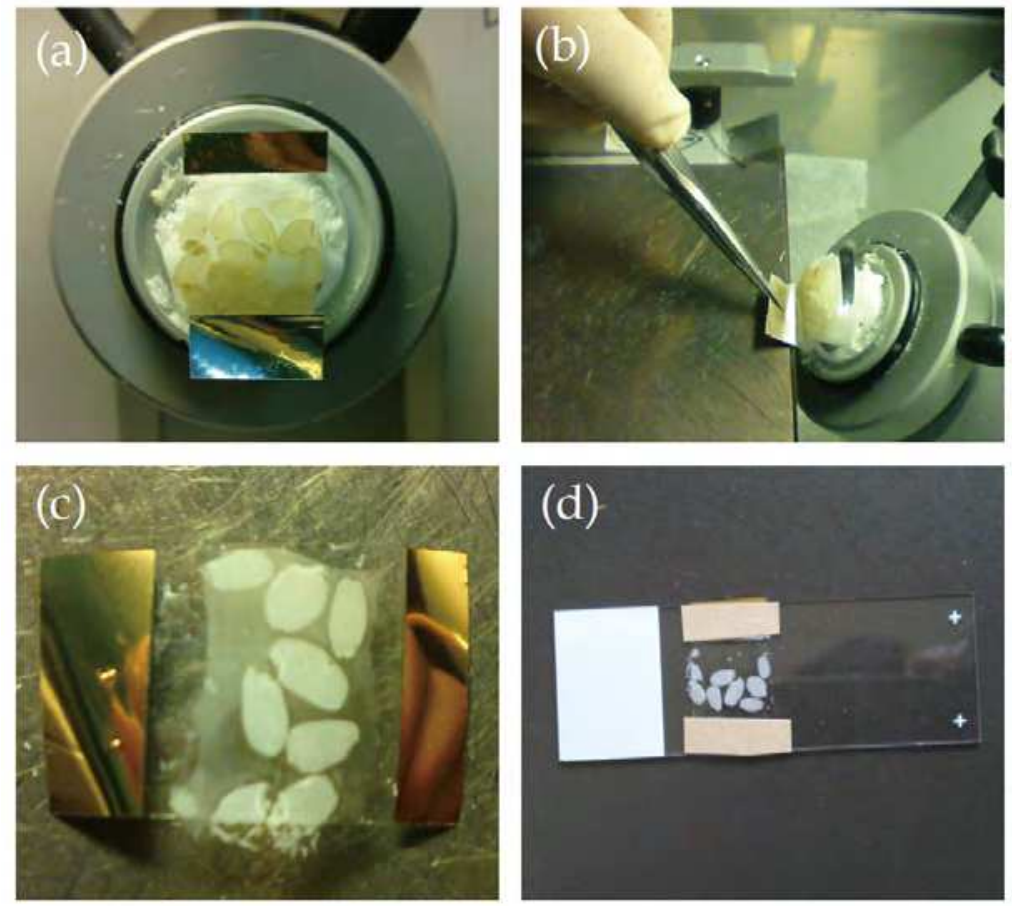

Fig. 3. Procedure for sectioning using adhesive film.

Attachment of adhesive film to the sample block (a). The end of the adhesive film must be anchored with tweezers to prevent adhesion of the film to the sample stage (b). After the sample section is obtained (c), the sample section on the adhesive film is attached to a glass slide (d).

\subsubsection{Washing}

Washing is required for peptide or protein analysis because their detection is often prevented by large amounts of easily ionized lipid species. Lipid removal simplifies mass spectra in the range of $\mathrm{m} / \mathrm{z} 400-1000$; thus, lipid removal enables the detection of low-mass peptides that are usually masked by lipid peaks. The washing method should be optimized for the target imaging molecules. Several washing protocols using organic solvents have been reported (Aerni et al., 2006; Andersson et al., 2008; Groseclose et al., 2007; Lemaire et al., 2006; Schwartz et al., 2003).

Washing is also used for removing the matrix from the tissue section after MALDI-IMS analysis. The matrix can be removed using the solvent that is used for preparing the matrix solution. For example, 2,5-dihydroxybenzoic acid (DHB) can be rapidly removed by methanol. Matrix removal enables the microscopic observation of a tissue section followed by pathological staining, such as hematoxylin and eosin (HE) staining, toluidine blue staining etc. 


\subsection{Matrix application}

The matrix plays a central role in MALDI-MS soft ionization (Karas \& Hillenkamp, 1988; Karas \& Kruger, 2003). Biomolecules are softly ionized in the cocrystal with the matrix, which absorbs the laser beam energy and protects biomolecules from the disruptive energy. Protonated ion $([\mathrm{M}+\mathrm{H}]+)$ or deprotonated ion $([\mathrm{M}-\mathrm{H}]-)$ molecules are generally detected. Sodium adduct ion $([\mathrm{M}+\mathrm{Na}]+)$ and potassium adduct ion $([\mathrm{M}+\mathrm{K}]+)$ are often observed by biological sample analysis. It is very important to choose appropriate matrices for obtaining meaningful biomolecular images. An overview of the matrices used for IMS can also be found in other reviews (Chughtai \& Heeren, 2010; Kaletas et al., 2009).

\subsubsection{Choice of matrix}

The choice of matrix used for MALDI-IMS depends on the mass range and chemical properties of the analytes. Among the many kinds of matrices, sinapinic acid (3,5-dimethoxy-4hydroxycinnamic acid [SA]) is generally used for high-molecular-weight molecules, such as proteins, while a-cyano-4-hydroxycinnamic acid (CHCA) is often used for medium-molecularweight molecules, such as peptides. 2,6-dihydroxyacetophenone (DHA), DHB, or 9aminoacridine (9-AA) is generally used for low-molecular-weight molecules, such as pharmaceutical compounds, lipids, or metabolites (Hattori et al., 2010; Hayasaka et al., 2009; Khatib-Shahidi et al., 2006; Sugiura et al., 2009; Woods \& Jackson, 2006).

The development of new matrices is still being reported. We and other research groups recently reported the use of nanoparticles as new matrices (Hayasaka et al., 2010; McLean et al., 2005; Moritake et al., 2009; Su \& Tseng, 2007; Sugiura \& Setou, 2010). For example, iron oxide nanoparticles enable the visualization of sulfatide and phospholipid distribution (Ageta et al., 2009; Taira et al., 2008), silver nanoparticles can be used for the analysis of fatty acids (Hayasaka et al., 2010), and gold nanoparticles are appropriate for the sensitive detection of glycosphingolipids, such as sulfatides and gangliosides (Goto-Inoue et al., 2010a).

\subsubsection{Matrix application}

There are various methods for applying the matrix onto the section, such as deposition, spraying, and sublimation. The matrix application method also influences analyte extraction efficiency. Compared to other methods, the deposition of matrix solution using automatic depositing robotic devices, such as a chemical inkjet printer (ChIP-1000; Shimadzu Corporation, Kyoto, Japan), increases signal sensitivity, but decreases spatial resolution (Aerni et al., 2006; Chansela et al., 2011; Morita et al., 2010). The other limitation of the inkjet printer is capillary clogging, which occurs when highly concentrated matrix solutions are used. Spraying is the most frequently used method in MALDI-IMS. Using this method, an entire tissue section can be homogeneously coated with relatively small crystals in a short time without special equipment. For its operation, several instruments, including Thin layer chromatography (TLC) sprayers and artistic airbrushes, are available; we use a metal airbrush with a 0.2-mm nozzle because of its simple and easy-to-handle design. This method requires skillful operation because some airbrush parameters are hand-operated. If there is an excess of matrix solution on the tissue, an inhomogeneous crystal can be formed with analytes that have migrated from their original location; on the other hand, if not enough matrix solution is sprayed and it evaporates without sufficiently moisturizing the tissue section, analytes cannot 
be adequately extracted from the tissue section. The operation should be performed at a constant room temperature and humidity. Beginners are recommended to practice spraying until homogeneous matrix spraying can be reproducibly achieved. Sublimation is a new method for applying matrix to tissue sections (Hankin et al., 2007). Using this technique, a matrix can be applied uniformly over a large sample plate in a few minutes without solvents. Additionally, previous reports demonstrated that this method increases analyte signal and that the fine microcrystals formed from the condensed vapor reduce the image resolution limitation caused by crystal size (Dekker et al., 2009; Vrkoslav et al., 2010).

\subsection{Measurement and data analysis}

\subsubsection{Measurement}

MALDI-IMS should be performed as soon as possible after matrix application, regardless of the coating method. The procedure to obtain a good spectrum in MALDI-IMS is almost the same as that for traditional MALDI-MS; mass range, detector gain, and laser power must be optimized. From the mechanical setting perspective, there are 3 differences between MALDI-MS and MALDI-IMS. The first difference is the above-mentioned matrix application. The second difference is the need for focusing of the laser beam. To obtain meaningful biological images by MALDI-IMS, the laser spot size should be reduced to 10-50 $\mu \mathrm{m}$. The third difference is that a two-dimensional region must be set for analyses. The scan pitch, which signifies the distance between laser irradiation spots, must be fixed. The limitation of the scan pitch, which decides the spatial resolution of the image, depends on the laser spot size and mechanical movement control of the mass spectrometer sample stage. We have developed a new instrument (Mass Microscope) that can move the sample stage by $1 \mu \mathrm{m}$, and in which the finest size of the laser diameter is approximately $10 \mu \mathrm{m}$ (Harada et al., 2009). The measurement time depends on the number of data spots, the frequency of the laser, the number of shots per spot, and the time required to move the sample stage. For example, when researchers select the region of interest as a $1 \times 1 \mathrm{~mm}^{2}$ area with a $10-\mu \mathrm{m}$ scan pitch (10,000 data points), it takes about $1 \mathrm{~h}$ to complete the measurement using a mass microscope equipped with a 1000-Hz laser (100 shots/data point).

MALDI-IMS ionizes numerous compounds in a tissue at the same time. Sometimes, we detect multiple molecules with the same $\mathrm{m} / z$ value. In such cases, a new imaging technique, "MS/MS imaging," is effective. Using this technique, we can separate each ion derived from their specific fragment ions. Some reports have described the use of MS/MS imaging for IMS of endogenous metabolites and an exogenous drug (Khatib-Shahidi et al., 2006; Porta et al., 2011). Additionally, the combination of ion-mobility separation with MALDI-IMS provides a unique separation dimension to further enhance the capabilities of IMS (Jackson et al., 2007; McLean et al., 2007; Stauber et al., 2010). It can be used to produce images without interference from background ions of similar mass, and this can remove ambiguity from imaging experiments and lead to a more precise localization of the compound of interest.

\subsubsection{Data analysis}

A large amount of data (a few gigabytes) is obtained from MALDI-IMS; therefore, visualization software packages that can rapidly and efficiently analyze enormous spectra have been developed. BioMap (a free software; Novartis, Basel, Switzerland), FlexImaging 
(Bruker Daltonics, Bremen, Germany), and ImageQuest (Thermo Fisher Scientific, CA, USA) are generally used for visualization. For biomarker analysis of the MALDI-IMS dataset, data mining should be used (Hayasaka et al., 2011; Zaima et al., 2011b; Zhang et al., 2004). Data mining software effectively reduce the number of biomarker candidates (Hayasaka et al., 2011; Zhang et al., 2004). We previously reported the use of principal component analysis (PCA) to discover different biomolecules in starvation-induced fatty livers and normal livers (Zaima et al., 2009). Hierarchical clustering was also used to analyze the data obtained from gastric cancer and non-neoplastic mucosa tissue sections (Deininger et al., 2008). Several studies have reported the discovery of biomarkers using MALDI-IMS (Bakry et al., 2011; Ducret et al., 2006; Hong \& Zhang, 2011; Solassol et al., 2009; Zaima et al., 2011b).

\section{Instruments}

The requirement for performing IMS is the availability of an $x$-axis-y-axis moving stage with electronic controls. Most modern MS instruments produced by major MS hardware companies (i.e., Shimadzu, ThermoFisher Scientific, Bruker Daltonics, Applied Biosystems, Waters) can be adapted for MALDI-IMS. Time of flight (TOF) is the most widely used technology. TOF analyzers allow the separation of ionized accelerated molecules according to their $\mathrm{m} / \mathrm{z}$ ratio. TOF-MS offers suitable performance for MALDI-IMS, namely, good transmission ratio (50$100 \%$ ), sensitivity, mass range, and repetition rate. However, TOF-MS lacks the capability to perform effective tandem MS experiments. This disadvantage of TOF-MS was overcome with the introduction of hybrid analyzers, such as a combination of quadrupole mass analyzer and TOF (so-called qTOF), combination of quadrupole ion trap (QIT) and TOF (so-called QITTOF), combination of ion mobility spectrometry (IMS) and TOF (so-called IMS-TOF), or a combination of two TOF mass spectrometers (so-called TOF-TOF). These combination systems revolutionized the application of TOF-MS systems for structural analysis with tandem MS. In general, the first system is used to select a precursor ion for fragmentation, while the second TOF system is employed for fragment analysis. Other mass analyzers (and their combinations), such as linear ion trap (LIT) (Landgraf et al., 2009; Wiseman et al., 2006; Zaima et al., 2010a), triple quadrupole (QqQ) (Hopfgartner et al., 2009; Porta et al., 2011), and Fourier transform ion cyclotron resonance (FTICR) (Taban et al., 2007), are used for MALDI-IMS. The advantages of commercially available LIT instruments are miniaturization, capability of sample analysis on nonconductive glass slides, MALDI performance at intermediate pressure, and superior performance on multistage MS. The QqQ system allows quantitative analysis and single or multiple reaction monitoring (SRM/MRM). The FTICR system offers very high mass resolving power and high mass measurement accuracy.

\section{Applications of MALDI-IMS}

\subsection{Imaging mass spectrometry-based histopathologic examination}

Recently, we applied MALDI-IMS for pathologic examination of atherosclerotic aorta (Fig. 4). We named it imaging mass spectrometry-based histopathologic examination (IbHE) (Zaima et al., 2011c). IbHE revealed the characteristic distribution of biomolecules in smooth muscle cells, lipid-rich regions, and calcified regions of an atherosclerotic lesion obtained from aortic roots of apolipoprotein $\mathrm{E}$ (ApoE)-deficient mice. We found that phosphatidylcholine (PC), which contains arachidonic acid (20:4) (m/z 804.5), was distributed in the smooth muscle cells of the atherosclerotic lesion. Cholesterol linoleate (CE 
18:2) $(m / z$ 671.6) and cholesterol oleate (CE 18:1) were characteristically distributed in lipid-rich regions, and the ion at $m / z 566.9$ was localized in the calcified region. These biomolecules were hardly detected in the normal aortic roots of ApoE-deficient mice. We applied this method to other vascular diseases, such as varicose veins, arteriovenous fistulae, abdominal aortic aneurysm, and triglyceride deposit cardiomyovasculopathy, and observed the characteristic distribution of biomolecules (Tanaka et al., 2010; Tanaka et al., 2011). In the analysis of several vascular diseases with atherosclerotic lesions, we often observed ectopic TG distribution. Although the role of TG in the evolution of atherosclerosis remains unknown, there is a possibility that TG plays an important role in the evolution of some kinds of atherosclerosis, as we previously found that characteristic atherosclerosis accumulated TG in aortic lesions, while the accumulated cholesterol was normal (Hirano et al., 2008). The reexamination of vascular diseases by IbHE may result in new findings, because IbHE can visualize the localization of low-molecular-weight molecules, which are rarely visualized by other techniques. We believe $\mathrm{IbHE}$ is of considerable value as a new histopathological examination because IbHE can visualize metabolic abnormalities in disease.
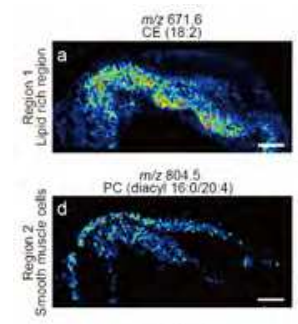

$m / 25669$
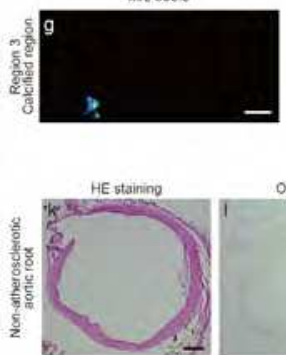

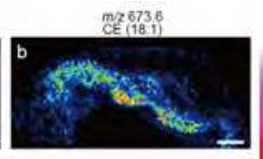
PC (diach 8325 18:0204)
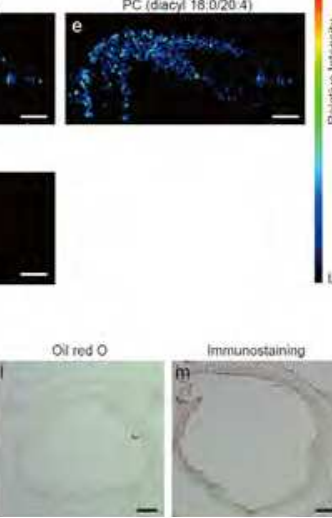

Imenunostaining
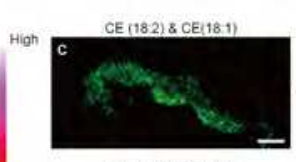

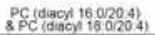

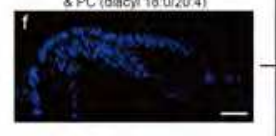

$m / 25689$
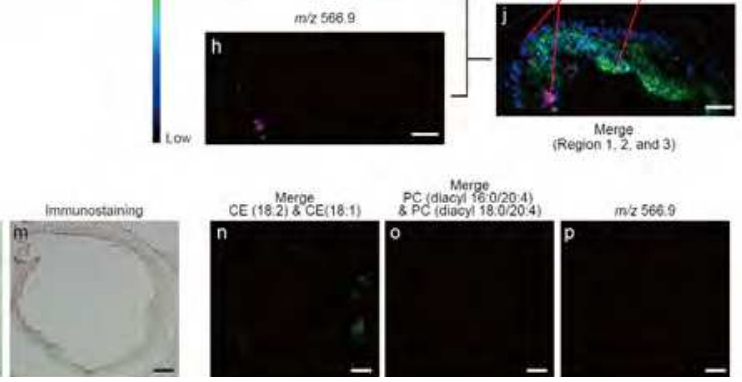

Fig. 4. Representative molecular images of specific ions in a mouse atherosclerotic lesion.

Visualization of biomolecules in atherosclerotic roots (a-j). Scale bar, $100 \mu \mathrm{m}$. Specific ion images of region 1 (a and b) and the combined image of $m / z 671.6$ and 673.6 (c). Specific ion images of region 2 (d and e) and the combined image of $m / z 804.5$ and 832.5 (f). Specific ion images of region $3(\mathrm{~g})$ and the monochrome image of $m / z 566.9(\mathrm{~h})$. Comparison of HE staining (i) and the merge images of regions 1, 2, and 3 (j). An image of non-atherosclerotic aortic roots of mice at 12 weeks of age (k-m). Scale bar, $200 \mu \mathrm{m}$. HE staining after IMS (k). Oil red O staining (l). Immunostaining of a-actin, which is a marker for smooth muscle cells (m). Merge image of CE (18:2) and CE (18:1) (n). Merge image of PC (diacyl 16:0/20:4) and PC (diacyl 18:0/20:4) (o). Ion image of $m / z 566.9$ (p). "Reprinted from Atherosclerosis, 217. 2, Zaima et al., Imaging mass spectrometry-based histopathologic examination of atherosclerotic lesions, 430., Copyright (2011), with permission from Elsevier." 


\subsection{IMS for exogenous drugs}

MALDI-IMS is a powerful tool for visualizing the distribution of exogenous drugs and their metabolites. Porta et al. reported the visualization of the distribution of cocaine and its metabolites down to a concentration of $5 \mathrm{ng} / \mathrm{mg}$ in intact single hair samples from chronic users (Porta et al., 2011) (Fig. 5).

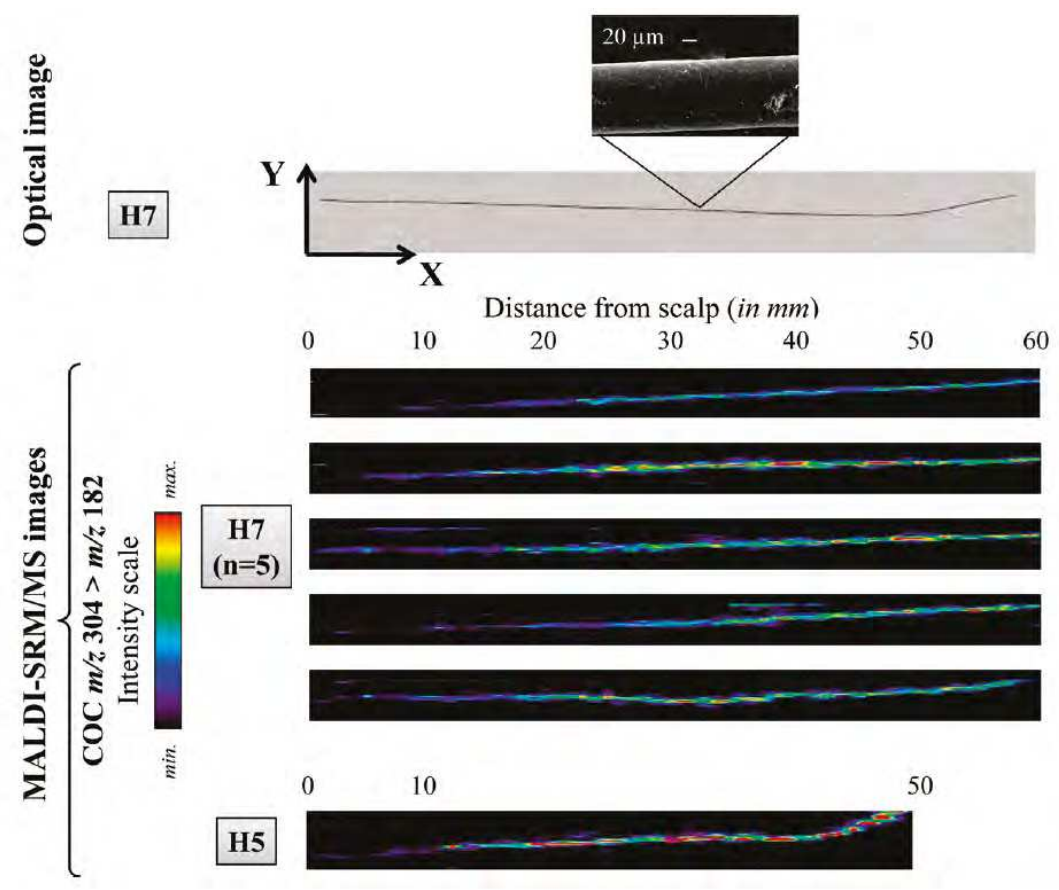

(a)

(b)

Fig. 5. Imaging of cocaine in hair samples $\mathrm{H} 7$ and $\mathrm{H} 5$. (H7 and $\mathrm{H} 5$ are sample names used in this article)

Optical image of hair sample H7 (a). MALDI-SRM/MS image based on the SRM trace of COC (m/z $305>$ m/z 182) for five replicates of single hair samples from individual H7 (b) and single hair analysis from individual $\mathrm{H} 5$ (c). The quantitative results from LC-SRM/MS routine analysis were as follows: $130 \mathrm{ng} / \mathrm{mg}$ (H7, whole sample); $4.9 \mathrm{ng} / \mathrm{mg}$ (H5, segment 0-10 mm), and $8.5 \mathrm{ng} / \mathrm{mg}$ (H5, segment 10-50 mm). SRM; selected reaction monitoring. "Reprinted with permission from Porta et al., 2011. Copyright 2011 American Chemical Society."

MALDI-IMS is also applicable to pharmacokinetic analysis. As a Food and Drug Administration (FDA)-mandated pharmacokinetic test, whole-body autoradiography (WBA) is widely performed to determine spatial and quantitative information about a drug compound. Although much information can be acquired by WBA, it has several limitations. First, WBA requires the compound of interest to be radioactively labeled. Furthermore, the detected signal does not distinguish between the original radiolabeled compound and its metabolites that have retained the radiolabel. To complement the disadvantage of WBA, MALDI-IMS and WBA have recently been used together. The combination of MALDI-IMS and 
WBA makes it possible to obtain more reliable data for absorption, distribution, metabolism, and excretion of drugs (Atkinson et al., 2007; Caprioli et al., 2008; Clench et al., 2008; Stoeckli et al., 2006). The application of MALDI-IMS to pharmacokinetics in a whole-body mouse section was first reported by Rohner et al. in 2005 (Rohner et al., 2005). In this study, they showed a good correlation between WBA and MALDI-IMS data. Figure 5 shows the simultaneous visualization of drug and metabolites in a whole-rat sagittal tissue section (Khatib-Shahidi et al., 2006). Khatib-Shahidi et al. visualized the temporal distribution of dosed olanzapine (brand name Zyprexa) $(8 \mathrm{mg} / \mathrm{kg})$ and its metabolites. In this study, MALDI-IMS was further extended to detect proteins from organs present in a whole-body section.

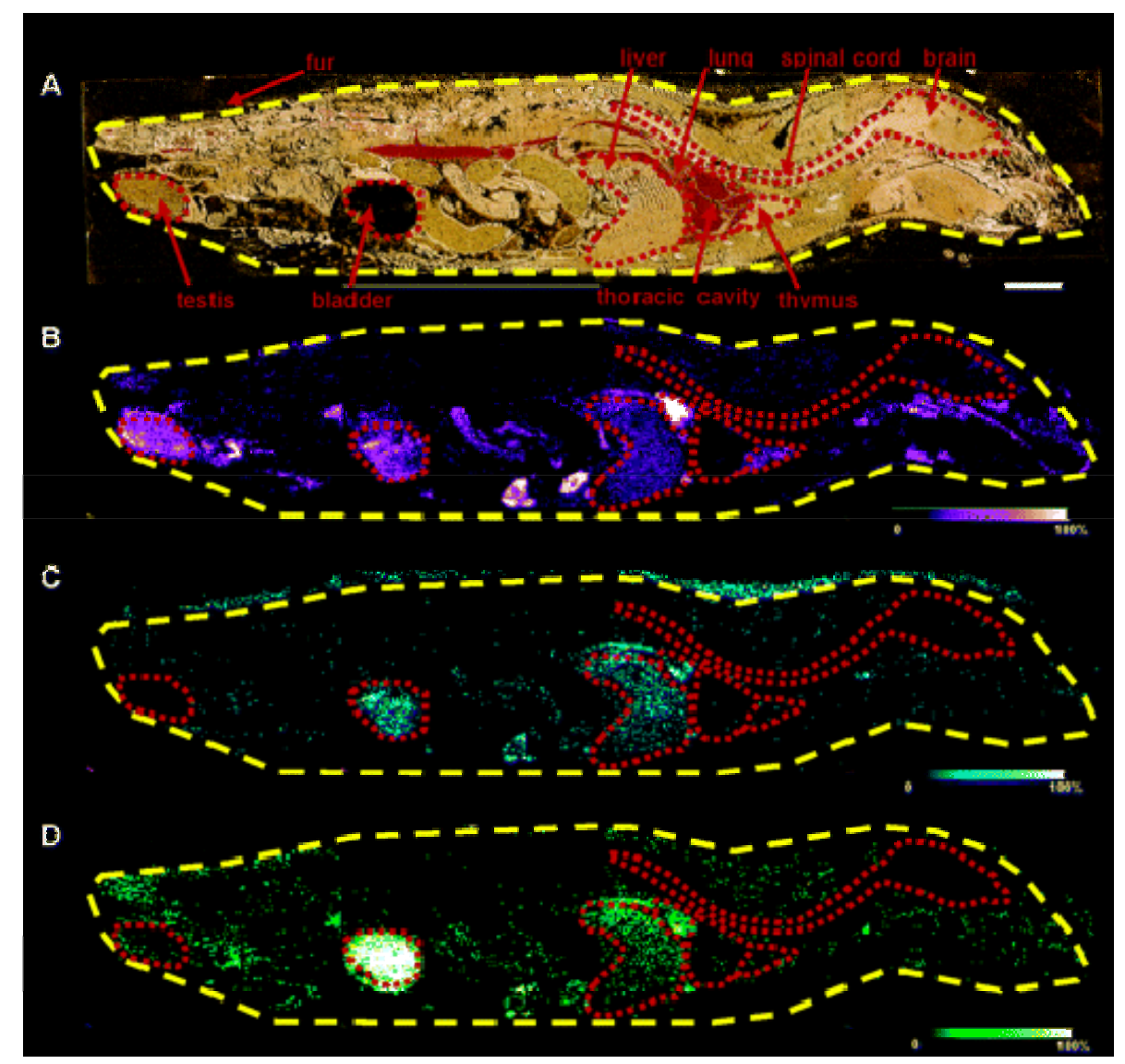

Fig. 6. Detection of drug and metabolite distribution at $6 \mathrm{~h}$ post-dose in a whole-rat sagittal tissue section by a single IMS analysis.

Optical images of a $6 \mathrm{~h}$ post-olanzapine (OLZ)-dosed rat tissue section across 4 gold MALDI target plates (A). Organs are outlined in red. MS/MS ion image of OLZ (m/z 256) (B). MS/MS ion image of N-desmethyl metabolite (m/z 256) (C). MS/MS ion image of 2hydroxymethyl metabolite (m/z 272) (D). Scale bar, $1 \mathrm{~cm}$. "Reprinted with permission from Khatib-Shahidi et al., 2006. Copyright 2006 American Chemical Society." 


\section{Conclusions}

MALDI-IMS can be applied to pathological examinations leading to the discovery of potential targets for new drugs, and for the distributional analysis of exogenous drugs in animal and human tissues. We recently used MALDI-IMS in the discovery of metabolites that have pharmacological effects on natural resources. MALDI-IMS will become an essential tool for molecular imaging in pharmacology in the near future.

\section{Acknowledgement}

This work was supported by the Program for Promotion of Basic and Applied Research for Innovations in Bio-oriented Industry (BRAIN).

\section{References}

Aerni, H. R., Cornett, D. S., \& Caprioli, R. M. (2006). Automated acoustic matrix deposition for MALDI sample preparation. Anal Chem 78.3, pp.827-34

Ageta, H., Asai, S., Sugiura, Y., Goto-Inoue, N., Zaima, N., \& Setou, M. (2009). Layer-specific sulfatide localization in rat hippocampus middle molecular layer is revealed by nanoparticle-assisted laser desorption/ionization imaging mass spectrometry. Med Mol Morphol 42.1, pp.16-23

Andersson, M., Groseclose, M. R., Deutch, A. Y., \& Caprioli, R. M. (2008). Imaging mass spectrometry of proteins and peptides: 3D volume reconstruction. Nat Methods 5.1, pp.101-108

Atkinson, S. J., Loadman, P. M., Sutton, C., Patterson, L. H., \& Clench, M. R. (2007). Examination of the distribution of the bioreductive drug $\mathrm{AQ} 4 \mathrm{~N}$ and its active metabolite AQ4 in solid tumours by imaging matrix-assisted laser desorption/ionisation mass spectrometry. Rapid Commun Mass Spectrom 21.7, pp.1271-6

Bakry, R., Rainer, M., Huck, C. W., \& Bonn, G. K. (2011). Protein profiling for cancer biomarker discovery using matrix-assisted laser desorption/ionization time-offlight mass spectrometry and infrared imaging: A review. Analytica Chimica Acta 690.1, pp.26-34

Caprioli, R. M., Cornett, D. S., \& Frappier, S. L. (2008). MALDI-FTICR imaging mass spectrometry of drugs and metabolites in tissue. Analytical Chemistry 80.14, pp.5648-5653

Caprioli, R. M., Farmer, T. B., \& Gile, J. (1997). Molecular imaging of biological samples: localization of peptides and proteins using MALDI-TOF MS. Anal Chem 69.23, pp.4751-60

Chansela, P., Goto-Inoue, N., Zaima, N., Sroyraya, M., Sobhon, P., \& Setou, M. (2011). Visualization of neuropeptides in paraffin-embedded tissue sections of the central nervous system in the decapod crustacean, Penaeus monodon, by imaging mass spectrometry. Peptides

Chen, R., Hui, L., Sturm, R. M., \& Li, L. (2009). Three dimensional mapping of neuropeptides and lipids in crustacean brain by mass spectral imaging. J Am Soc Mass Spectrom 20.6, pp.1068-77

Chughtai, K., \& Heeren, R. M. (2010). Mass spectrometric imaging for biomedical tissue analysis. Chem Rev 110.5, pp.3237-77 
Clench, M. R., Trim, P. J., Henson, C. M., Avery, J. L., McEwen, A., Snel, M. F., Claude, E., Marshall, P. S., West, A., \& Princivalle, A. P. (2008). Matrix-Assisted Laser Desorption/Ionization-Ion Mobility Separation-Mass Spectrometry Imaging of Vinblastine in Whole Body Tissue Sections. Analytical Chemistry 80.22, pp.8628-8634

Cornett, D. S., Reyzer, M. L., Chaurand, P., \& Caprioli, R. M. (2007). MALDI imaging mass spectrometry: molecular snapshots of biochemical systems. Nat Methods 4.10, pp.828-833

Deininger, S. O., Ebert, M. P., Futterer, A., Gerhard, M., \& Rocken, C. (2008). MALDI Imaging Combined with Hierarchical Clustering as a New Tool for the Interpretation of Complex Human Cancers. J Proteome Res 7.12, pp.5230-5236

Dekker, L. J., van Kampen, J. J., Reedijk, M. L., Burgers, P. C., Gruters, R. A., Osterhaus, A. D., \& Luider, T. M. (2009). A mass spectrometry based imaging method developed for the intracellular detection of HIV protease inhibitors. Rapid Commun Mass Spectrom 23.8, pp.1183-8

Djidja, M. C., Francese, S., Loadman, P. M., Sutton, C. W., Scriven, P., Claude, E., Snel, M. F., Franck, J., Salzet, M., \& Clench, M. R. (2009). Detergent addition to tryptic digests and ion mobility separation prior to MS/MS improves peptide yield and protein identification for in situ proteomic investigation of frozen and formalin-fixed paraffin-embedded adenocarcinoma tissue sections. Proteomics 9.10, pp.2750-63

Ducret, A., Meistermann, H., Norris, J. L., Aerni, H. R., Cornett, D. S., Friedlein, A., Erskine, A. R., Augustin, A., Mudry, M. C. D., Ruepp, S., Suter, L., Langen, H., \& Caprioli, R. M. (2006). Biomarker discovery by imaging mass spectrometry - Transthyretin is a biomarker for gentamicin-induced nephrotoxicity in rat. Molecular $\mathcal{E}$ Cellular Proteomics 5.10, pp.1876-1886

Goodwin, R. J., Pennington, S. R., \& Pitt, A. R. (2008). Protein and peptides in pictures: imaging with MALDI mass spectrometry. Proteomics 8.18, pp.3785-800

Goto-Inoue, N., Hayasaka, T., Zaima, N., Kashiwagi, Y., Yamamoto, M., Nakamoto, M., \& Setou, M. (2010a). The detection of glycosphingolipids in brain tissue sections by imaging mass spectrometry using gold nanoparticles. J Am Soc Mass Spectrom 21.11, pp.1940-3

Goto-Inoue, N., Setou, M., \& Zaima, N. (2010b). Visualization of spatial distribution of gamma-aminobutyric acid in eggplant (Solanum melongena) by matrix-assisted laser desorption/ionization imaging mass spectrometry. Anal Sci 26.7, pp.821-5

Groseclose, M. R., Andersson, M., Hardesty, W. M., \& Caprioli, R. M. (2007). Identification of proteins directly from tissue: in situ tryptic digestions coupled with imaging mass spectrometry. J Mass Spectrom 42.2, pp.254-62

Hankin, J. A., Barkley, R. M., \& Murphy, R. C. (2007). Sublimation as a method of matrix application for mass spectrometric imaging. J Am Soc Mass Spectrom 18.9, pp.1646-52

Harada, T., Yuba-Kubo, A., Sugiura, Y., Zaima, N., Hayasaka, T., Goto-Inoue, N., Wakui, M., Suematsu, M., Takeshita, K., Ogawa, K., Yoshida, Y., \& Setou, M. (2009). Visualization of volatile substances in different organelles with an atmosphericpressure mass microscope. Anal Chem 81.21, pp.9153-7

Hattori, K., Kajimura, M., Hishiki, T., Nakanishi, T., Kubo, A., Nagahata, Y., Ohmura, M., Yachie-Kinoshita, A., Matsuura, T., Morikawa, T., Nakamura, T., Setou, M., \& Suematsu, M. (2010). Paradoxical ATP Elevation in Ischemic Penumbra Revealed by Quantitative Imaging Mass Spectrometry. Antioxid Redox Signal 
Hayasaka, T., Goto-Inoue, N., Ushijima, M., Yao, I., Yuba-Kubo, A., Wakui, M., Kajihara, S., Matsuura, M., \& Setou, M. (2011). Development of imaging mass spectrometry (IMS) dataset extractor software, IMS convolution. Anal Bioanal Chem 401.1, pp.183-93

Hayasaka, T., Goto-Inoue, N., Zaima, N., Kimura, Y., \& Setou, M. (2009). Organ-specific distributions of lysophosphatidylcholine and triacylglycerol in mouse embryo. Lipids 44.9, pp.837-48

Hayasaka, T., Goto-Inoue, N., Zaima, N., Shrivas, K., Kashiwagi, Y., Yamamoto, M., Nakamoto, M., \& Setou, M. (2010). Imaging mass spectrometry with silver nanoparticles reveals the distribution of fatty acids in mouse retinal sections. J Am Soc Mass Spectrom 21.8, pp.1446-54

Hirano, K., Ikeda, Y., Zaima, N., Sakata, Y., \& Matsumiya, G. (2008). Triglyceride deposit cardiomyovasculopathy. N Engl J Med 359.22, pp.2396-8

Hong, D., \& Zhang, F. Q. (2011). Elastic net-based framework for imaging mass spectrometry data biomarker selection and classification. Statistics in Medicine 30.7, pp.753-768

Hopfgartner, G., Varesio, E., \& Stoeckli, M. (2009). Matrix-assisted laser desorption/ionization mass spectrometric imaging of complete rat sections using a triple quadrupole linear ion trap. Rapid Commun Mass Spectrom 23.6, pp.733-6

Jackson, S. N., Ugarov, M., Egan, T., Post, J. D., Langlais, D., Albert Schultz, J., \& Woods, A. S. (2007). MALDI-ion mobility-TOFMS imaging of lipids in rat brain tissue. J Mass Spectrom 42.8, pp.1093-8

Kaletas, B. K., van der Wiel, I. M., Stauber, J., Guzel, C., Kros, J. M., Luider, T. M., \& Heeren, R. M. (2009). Sample preparation issues for tissue imaging by imaging MS. Proteomics 9.10, pp.2622-33

Karas, M., Bachmann, D., \& Hillenkamp, F. (1985). Influence of the Wavelength in HighIrradiance Ultraviolet-Laser Desorption Mass-Spectrometry of Organic-Molecules. Analytical Chemistry 57.14, pp.2935-2939

Karas, M., \& Hillenkamp, F. (1988). Laser desorption ionization of proteins with molecular masses exceeding 10,000 daltons. Anal Chem 60.20, pp.2299-301

Karas, M., \& Kruger, R. (2003). Ion formation in MALDI: the cluster ionization mechanism. Chem Rev 103.2, pp.427-40

Khatib-Shahidi, S., Andersson, M., Herman, J. L., Gillespie, T. A., \& Caprioli, R. M. (2006). Direct molecular analysis of whole-body animal tissue sections by imaging MALDI mass spectrometry. Anal Chem 78.18, pp.6448-56

Landgraf, R. R., Conaway, M. C. P., Garrett, T. J., Stacpoole, P. W., \& Yost, R. A. (2009). Imaging of Lipids in Spinal Cord Using Intermediate Pressure Matrix-Assisted Laser Desorption-Linear Ion Trap/Orbitrap MS. Anal Chem 81.20, pp.8488-8495

Lemaire, R., Menguellet, S. A., Stauber, J., Marchaudon, V., Lucot, J. P., Collinet, P., Farine, M. O., Vinatier, D., Day, R., Ducoroy, P., Salzet, M., \& Fournier, I. (2007). Specific MALDI imaging and profiling for biomarker hunting and validation: fragment of the $11 S$ proteasome activator complex, Reg alpha fragment, is a new potential ovary cancer biomarker. J Proteome Res 6.11, pp.4127-34

Lemaire, R., Wisztorski, M., Desmons, A., Tabet, J. C., Day, R., Salzet, M., \& Fournier, I. (2006). MALDI-MS direct tissue analysis of proteins: Improving signal sensitivity using organic treatments. Anal Chem 78.20, pp.7145-53

McLean, J. A., Ridenour, W. B., \& Caprioli, R. M. (2007). Profiling and imaging of tissues by imaging ion mobility-mass spectrometry. J Mass Spectrom 42.8, pp.1099-105 
McLean, J. A., Stumpo, K. A., \& Russell, D. H. (2005). Size-selected (2-10 nm) gold nanoparticles for matrix assisted laser desorption ionization of peptides. J Am Chem Soc 127.15, pp.5304-5

Morita, Y., Ikegami, K., Goto-Inoue, N., Hayasaka, T., Zaima, N., Tanaka, H., Uehara, T., Setoguchi, T., Sakaguchi, T., Igarashi, H., Sugimura, H., Setou, M., \& Konno, H. (2010). Imaging mass spectrometry of gastric carcinoma in formalin-fixed paraffinembedded tissue microarray. Cancer Sci 101.1, pp.267-73

Moritake, S., Taira, S., Sugiura, Y., Setou, M., \& Ichiyanagi, Y. (2009). Magnetic nanoparticlebased mass spectrometry for the detection of biomolecules in cultured cells. J Nanosci Nanotechnol 9.1, pp.169-76

Murphy, R. C., Hankin, J. A., \& Barkley, R. M. (2009). Imaging of lipid species by MALDI mass spectrometry. J Lipid Res 50 Suppl. pp.S317-22

Porta, T., Grivet, C., Kraemer, T., Varesio, E., \& Hopfgartner, G. (2011). Single hair cocaine consumption monitoring by mass spectrometric imaging. Anal Chem 83.11, pp.4266-72

Rohner, T. C., Staab, D., \& Stoeckli, M. (2005). MALDI mass spectrometric imaging of biological tissue sections. Mech Ageing Dev 126.1, pp.177-85

Schwartz, S. A., Reyzer, M. L., \& Caprioli, R. M. (2003). Direct tissue analysis using matrixassisted laser desorption/ionization mass spectrometry: practical aspects of sample preparation. J Mass Spectrom 38.7, pp.699-708

Solassol, J., Mange, A., Chaurand, P., Perrochia, H., Roger, P., \& Caprioli, R. M. (2009). Liquid Chromatography-Tandem and MALDI Imaging Mass Spectrometry Analyses of RCL2/CS100-Fixed, Paraffin-Embedded Tissues: Proteomics Evaluation of an Alternate Fixative for Biomarker Discovery. Journal of Proteome Research 8.12, pp.5619-5628

Stauber, J., MacAleese, L., Franck, J., Claude, E., Snel, M., Kaletas, B. K., Wiel, I. M., Wisztorski, M., Fournier, I., \& Heeren, R. M. (2010). On-tissue protein identification and imaging by MALDI-ion mobility mass spectrometry. J Am Soc Mass Spectrom 21.3, pp.338-47

Stoeckli, M., Staab, D., \& Schweitzer, A. (2006). Compound and metabolite distribution measured by MALDI mass spectrometric imaging in whole-body tissue sections. Int J Mass Spectrom 260.2-3, pp.195-202

Stoeckli, M., Staab, D., Staufenbiel, M., Wiederhold, K. H., \& Signor, L. (2002). Molecular imaging of amyloid beta peptides in mouse brain sections using mass spectrometry. Anal Biochem 311.1, pp.33-9

$\mathrm{Su}, \mathrm{C}$. L., \& Tseng, W. L. (2007). Gold nanoparticles as assisted matrix for determining neutral small carbohydrates through laser desorption/ionization time-of-flight mass spectrometry. Anal Chem 79.4, pp.1626-33

Sugiura, Y., Konishi, Y., Zaima, N., Kajihara, S., Nakanishi, H., Taguchi, R., \& Setou, M. (2009). Visualization of the cell-selective distribution of PUFA-containing phosphatidylcholines in mouse brain by imaging mass spectrometry. J Lipid Res 50.9, pp.1776-88

Sugiura, Y., \& Setou, M. (2010). Matrix-assisted laser desorption/ionization and nanoparticle-based imaging mass spectrometry for small metabolites: a practical protocol. Methods Mol Biol 656. pp.173-95

Taban, I. M., Altelaar, A. F. M., Van der Burgt, Y. E. M., McDonnell, L. A., Heeren, R. M. A., Fuchser, J., \& Baykut, G. (2007). Imaging of peptides in the rat brain using MALDIFTICR mass spectrometry. J Am Soc Mass Spectrom 18.1, pp.145-151 
Taira, S., Sugiura, Y., Moritake, S., Shimma, S., Ichiyanagi, Y., \& Setou, M. (2008). Nanoparticle-assisted laser desorption/ionization based mass imaging with cellular resolution. Anal Chem 80.12, pp.4761-6

Tanaka, H., Zaima, N., Yamamoto, N., Sagara, D., Suzuki, M., Nishiyama, M., Mano, Y., Sano, M., Hayasaka, T., Goto-Inoue, N., Sasaki, T., Konno, H., Unno, N., \& Setou, M. (2010). Imaging mass spectrometry reveals unique lipid distribution in primary varicose veins. Eur J Vasc Endovasc Surg 40.5, pp.657-63

Tanaka, H., Zaima, N., Yamamoto, N., Suzuki, M., Mano, Y., Konno, H., Unno, N., \& Setou, M. (2011). Distribution of phospholipid molecular species in autogenous access grafts for hemodialysis analyzed using imaging mass spectrometry. Anal Bioanal Chem 400.7, pp.1873-80

Tanaka, K., Ido, Y., Akita, S., Yoshida, Y., \& Yoshida, T. (1987). Detection of High Mass Molecules by Laser Desorption Time-Of-Flight Mass Spectrometry. Proc. JapanChina Joint Symp. Mass Spectrom., pp.185

Vrkoslav, V., Muck, A., Cvacka, J., \& Svatos, A. (2010). MALDI imaging of neutral cuticular lipids in insects and plants. J Am Soc Mass Spectrom 21.2, pp.220-31

Wiseman, J. M., Ifa, D. R., Song, Q., \& Cooks, R. G. (2006). Tissue imaging at atmospheric pressure using desorption electrospray ionization (DESI) mass spectrometry. Angew Chem Int Ed Engl 45.43, pp.7188-92

Woods, A. S., \& Jackson, S. N. (2006). Brain tissue lipidomics: direct probing using matrixassisted laser desorption/ionization mass spectrometry. AAPS J 8.2, pp.E391-5

Yates, J. R., 3rd (1998). Mass spectrometry and the age of the proteome. J Mass Spectrom 33.1, pp.1-19

Zaima, N., Goto-Inoue, N., Adachi, K., \& Setou, M. (2011a). Selective analysis of lipids by thin-layer chromatography blot matrix-assisted laser desorption/ionization imaging mass spectrometry. J Oleo Sci 60.2, pp.93-8

Zaima, N., Goto-Inoue, N., Hayasaka, T., Enomoto, H., \& Setou, M. (2011b). Authenticity assessment of beef origin by principal component analysis of matrix-assisted laser desorption/ionization mass spectrometric data. Anal Bioanal Chem 400.7, pp.1865-71

Zaima, N., Goto-Inoue, N., Hayasaka, T., \& Setou, M. (2010a). Application of imaging mass spectrometry for the analysis of Oryza sativa rice. Rapid Commun Mass Spectrom 24.18, pp.2723-9

Zaima, N., Hayasaka, T., Goto-Inoue, N., \& Setou, M. (2010b). Matrix-assisted laser desorption/ionization imaging mass spectrometry. Int J Mol Sci 11.12, pp.5040-55

Zaima, N., Matsuyama, Y., \& Setou, M. (2009). Principal component analysis of direct matrix-assisted laser desorption/ionization mass spectrometric data related to metabolites of fatty liver. J Oleo Sci 58.5, pp.267-73

Zaima, N., Sasaki, T., Tanaka, H., Cheng, X. W., Onoue, K., Hayasaka, T., Goto-Inoue, N., Enomoto, H., Unno, N., Kuzuya, M., \& Setou, M. (2011c). Imaging mass spectrometry-based histopathologic examination of atherosclerotic lesions. Atherosclerosis 217.2, pp.427-32

Zhang, X., Leung, S. M., Morris, C. R., \& Shigenaga, M. K. (2004). Evaluation of a novel, integrated approach using functionalized magnetic beads, bench-top MALDI-TOFMS with prestructured sample supports, and pattern recognition software for profiling potential biomarkers in human plasma. J Biomol Tech 15.3, pp.167-75 


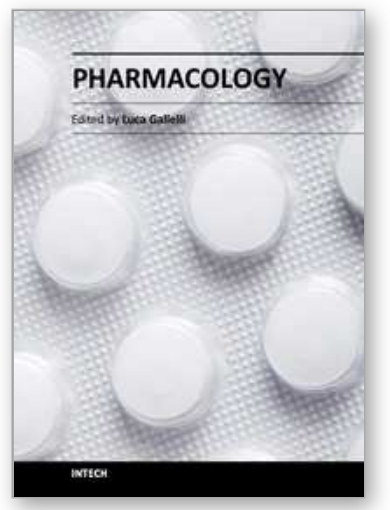

\author{
Pharmacology \\ Edited by Dr. Luca Gallelli
}

ISBN 978-953-51-0222-9

Hard cover, 720 pages

Publisher InTech

Published online 14, March, 2012

Published in print edition March, 2012

The history of pharmacology travels together to history of scientific method and the latest frontiers of pharmacology open a new world in the search of drugs. New technologies and continuing progress in the field of pharmacology has also changed radically the way of designing a new drug. In fact, modern drug discovery is based on deep knowledge of the disease and of both cellular and molecular mechanisms involved in its development. The purpose of this book was to give a new idea from the beginning of the pharmacology, starting from pharmacodynamic and reaching the new field of pharmacogenetic and ethnopharmacology.

\title{
How to reference
}

In order to correctly reference this scholarly work, feel free to copy and paste the following:

Nobuhiro Zaima (2012). Application of Matrix-Assisted Laser Desorption/lonization Imaging Mass Spectrometry, Pharmacology, Dr. Luca Gallelli (Ed.), ISBN: 978-953-51-0222-9, InTech, Available from: http://www.intechopen.com/books/pharmacology/application-of-matrix-assisted-laser-desorption-ionizationimaging-mass-spectrometry-for-pharmacolog

\section{INTECH}

open science / open minds

\section{InTech Europe}

University Campus STeP Ri

Slavka Krautzeka 83/A

51000 Rijeka, Croatia

Phone: +385 (51) 770447

Fax: +385 (51) 686166

www.intechopen.com

\section{InTech China}

Unit 405, Office Block, Hotel Equatorial Shanghai

No.65, Yan An Road (West), Shanghai, 200040, China

中国上海市延安西路65号上海国际贵都大饭店办公楼405单元

Phone: +86-21-62489820

Fax: +86-21-62489821 
(C) 2012 The Author(s). Licensee IntechOpen. This is an open access article distributed under the terms of the Creative Commons Attribution 3.0 License, which permits unrestricted use, distribution, and reproduction in any medium, provided the original work is properly cited. 